\title{
Correction: Screening for a new primary cancer in patients with existing metastatic cancer: a retrospective cohort study
}

Errors occurred in an article published on Nov. 7, 2018. ${ }^{1}$ In Table 1 , the colonoscopy value for patients with breast cancer should have been 2.7-3.1. Also, the flexible sigmoidoscopy and colonoscopy values for patients with breast cancer should have included the symbol linking to the footnote "* Small cell sizes were suppressed to preserve patient anonymity." These errors have been corrected at cmajopen.ca.

\section{Reference}

1. Cheung MC, Tinmouth J, Austin PC, et al. Screening for a new primary cancer in patients with existing metastatic cancer: a retrospective cohort study. CMA7 Open 2018;6:E538-43.

CMAJ Open 2018. DOI:10.9778/cmajo.20180186 